\title{
FNAC study of thyroid lesions using the Bethesda system
}

\author{
Dhamecha M.P. ${ }^{1}$, Swami S.Y. ${ }^{2}$, Valand A.G. ${ }^{3}$ \\ ${ }^{1}$ Dr. Mitali P. Dhamecha, Post Graduate, ${ }^{2}$ Dr. Sunil Y. Swami, Associate Professor, ${ }^{3}$ Dr. Arvind. G. Valand, Professor, \\ all authors are affiliated with Swami Ramanand Teerth Rural Government Medical College, Ambajogai, Maharashtra \\ 431517, India.
}

Corresponding Author: Dr. Sunil Y. Swami, Email: drsys02@gmail.com

\begin{abstract}
Background: The most reliable, safe, cost-effective and accurate way to evaluate thyroid nodule is cytology, which has become the standard of care. As there is a $10 \%$ lifetime risk of developing a thyroid nodule, screening thyroid nodules had turned out to become a common medical problem affecting the general population. According to the guidelines of American association of clinical endocrinologists, fine needle aspiration cytology [FNAC] is the gold standard method available for distinguishing between benign and malignant thyroid swelling and is the most commonly performed nongynaecological cytological procedure. Aims: To study the cytomorphological features and to classify cytologically the thyroid lesions based on the Bethesda system. Methods and Material: The present descriptive study was undertaken in a tertiary care hospital for a period of 3 years to analyse the role of FNAC in the diagnosis of thyroid lesions and classify them cytologically according to the Bethesda system. Results: 40 cases were classified as unsatisfactory, 328 cases as benign, 5 cases as AUS, 23 cases as FN/ HCN, 1 case as SFM and 3 cases as malignant. Out of 328 cases in benign category, 281cases belonged to BFNsubcategory which was the most common non-neoplastic lesion of thyroid.The age range of patients presenting with the thyroid lesion was from 7-75 years. Maximum number of cases i.e. 116 were in the age group 31-40 years followed by 95 cases in the age group 21-30 years. Maximum cases in the benign category belonged to the age group of 31- 40 years. Maximum cases [10 out of 23 cases] in the follicular neoplasm category were seen in the age group ranging 21-40 years. Out of 400 cases, females [359] cases outnumbered male [41] cases contributing $89.75 \%$ and $10.25 \%$ respectively with male to female ratio of $1: 8.7$. There was overall female preponderance seen in all diagnostic categories of TBSRTC. 5 cases diagnosed as AUS in our study were according to recommended criteria mentioned in Bethesda system i.e. less than 7\%. One case each of PTC, MTC and UTC were seen in malignant category in our study. Conclusions: The Bethesda System for Reporting Thyroid Cytopathology (TBSRTC) helped to communicate interpretations of thyroid FNAC to referring physicians in terms that are short, concise and clinically helpful and it will also be a source of information for pathologists as well.
\end{abstract}

Keywords: Bethesda, Aspiration, Thyroid, Cytology.

\section{Introduction}

Thyroid gland is affected by a vast array of disorders like developmental, inflammatory, hyperplastic and neoplastic disorders. The incidence of palpable thyroid swelling is $4-7 \%$ [1]. A thyroid enlargement whether diffuse or in the form of a nodule has to be investigated to rule out neoplasm [2]. Only about $20 \%$ of patients undergoing thyroid surgery for suspicion of carcinoma actually show the histology of malignancy [3].

The FNAC [Fine Needle Aspiration Cytology] showed the importance of suspicious thyroid swellings in

Manuscript received: $10^{\text {th }}$ March 2018

Reviewed: $20^{\text {th }}$ March 2018

Author Corrected: $26^{\text {th }}$ March 2018

Accepted for Publication: $31^{\text {st }}$ March 2018 cytology as an indication for surgery and decreased the overall incidence of thyroidectomy in patients with benign disease. The FNAC provide highly accurate cytologic information from which a definitive management plan could be arranged with high sensitivity and specificity approaching to $96 \%$. [4].

Aims and objectives of the study were to classify cytologically the FNAC of thyroid lesions as per the Bethesda system, to study the cytomorphological features in thyroid lesions and to study the clinic cytopathological correlation in patients with thyroid lesions. 


\section{Original Research Article}

\section{Material \& Methods}

Place and duration of study: The present descriptive study was undertaken in a tertiary care hospital for a period of 3 years to analyse the role of FNAC in the diagnosis of thyroid lesions and classify them cytologically according to the Bethesda system.

Inclusion criteria: All the cases of palpable thyroid swelling who were referred for FNAC were included in the present study.

Exclusion criteria: Neck swellings other than thyroid are excluded from the study.

A detailed clinical history was obtained and a through clinical examination was done prior to procuring sample for the cytological study. Written informed consent was obtained and the proper information regarding the procedure was given to the patient. Thyroid FNAC was done with patient lying comfortably in a supine position or sitting position and the neck was extended so as to make the swelling appear prominent. The fine needle aspiration was performed by either fixing the swelling by palpation or under ultrasound (US) guidance with a 23-24-gauge needle attached to $10 \mathrm{ml}$ disposable syringe and under all aseptic precautions.

The obtained material was spread on glass slides of $75 \mathrm{x}$ $25 \times 1.35 \mathrm{~mm}$. The slides were kept dry for Giemsa staining and those for PAP [Papanicolaou] staining was fixed in $95 \%$ ethanol. The patients were instructed to restrain from swallowing and speaking during the procedure. The FNAC smears were examined microscopically after staining and the results were categorized into 6 diagnostic categories according to the Bethesda System for reporting thyroid cytopathology.

\section{Results}

The present study included a total of 400 thyroid lesions.

Table-1: Distribution of thyroid lesions according to the Bethesda diagnostic categories.

\begin{tabular}{|c|c|c|c|}
\hline & Bethesda diagnostic categories & Number of cases & Percentage (\%) \\
\hline 1 & Unsatisfactory [UNS]/ Non-diagnostic. & 40 & 10 \\
\hline 2 & Benign. & 328 & 82 \\
\hline 3 & Atypia of undetermined significance [AUS] & 5 & 1.25 \\
\hline 4 & Follicular neoplasm [FN]/ Hürthle cell neoplasm [HCN] & 23 & 5.75 \\
\hline 5 & Suspicious for malignancy[SFM] & 1 & 0.25 \\
\hline 6 & Malignant & 3 & 0.75 \\
\hline & Total & $\mathbf{4 0 0}$ & $\mathbf{1 0 0}$ \\
\hline
\end{tabular}

In the present study of 400 cases, 328 [82\%] cases were benign followed by 23 [5.75\%] cases of FN/ HCN, 5 [1.25\%] cases of AUS, 3 [0.75\%] cases of malignant neoplasms and only 1 [0.25\%] case of SFM.

$40[10 \%]$ cases were unsatisfactory or non-diagnostic.

Table-2:Distribution of cases according to age and Bethesda diagnostic categories:

\begin{tabular}{|c|c|c|c|c|c|c|c|}
\hline \multirow{2}{*}{$\begin{array}{c}\text { Age } \\
(\text { years })\end{array}$} & \multicolumn{9}{|c|}{ Bethesda diagnostic categories } & Total \\
\cline { 2 - 8 } & UNS & Benign & AUS/FLUS & FN/HCN & SFM & Malignant & \\
\hline $1-10$ & 0 & 3 & 0 & 0 & 0 & 0 & 03 \\
\hline $11-20$ & 5 & 36 & 1 & 3 & 0 & 1 & 46 \\
\hline $21-30$ & 10 & 77 & 3 & 5 & 0 & 0 & 95 \\
\hline $31-40$ & 17 & 91 & 1 & 5 & 1 & 1 & 116 \\
\hline $41-50$ & 6 & 48 & 0 & 4 & 0 & 0 & 58 \\
\hline $51-60$ & 1 & 39 & 0 & 3 & 0 & 1 & 44 \\
\hline $61-70$ & 0 & 34 & 0 & 3 & 0 & 0 & 37 \\
\hline $71-80$ & 1 & 0 & 0 & 0 & 0 & 0 & 01 \\
\hline Total & $\mathbf{4 0}$ & $\mathbf{3 2 8}$ & $\mathbf{5}$ & $\mathbf{2 3}$ & $\mathbf{1}$ & $\mathbf{3}$ & $\mathbf{4 0 0}$ \\
\hline
\end{tabular}




\section{Original Research Article}

In the present study,116 [29\%] patients were in the age range of 31- 40 years, followed by 95 [23.75\%] patients in the age range of 21-30 years. Minimum number of patients belonged to the age group of 71- 80 years i.e. 1 patient [0.25\%]. The mean age of the patients was 38.53 years, ranging between 7-75 years. The maximum 91 [27.74\%] cases in 328 benign lesions category belonged to the age group of 31- 40 years followed by 77 [23.47\%] cases in age group 21- 30 years. Out of 23 cases in the FN category, maximum 10 cases were seen in the age group ranging $21-40$ years. 1 case diagnosed as SFM was seen in age group 31- 40 years.

The 3 diagnosed malignant cases were in the age group 11- 30, 31- 40, 51- 60 years each.

Table-3: Distribution of cases as per gender and Bethesda diagnostic categories:

\begin{tabular}{|c|c|c|c|c|c|c|c|}
\hline Sex & UNS & Benign & AUS & FN/ HCN & SFM & Malignant & Total [\%] \\
\hline Male & 3 & 35 & 1 & 1 & 0 & 1 & $41[10.25]$ \\
\hline Female & 37 & 293 & 4 & 22 & 1 & 2 & $359[89.75]$ \\
\hline Total & $\mathbf{4 0}$ & $\mathbf{3 2 8}$ & $\mathbf{5}$ & $\mathbf{2 3}$ & $\mathbf{1}$ & $\mathbf{3}$ & $\mathbf{4 0 0}$ \\
\hline
\end{tabular}

In the present study, out of total 400 cases 359 [89.75\%] were females and 41 [10.25\%] were males with male to female ratio of $1: 8.7$.

Table-4: Distribution of cases in the sub categories of the Bethesda diagnostic categories:

\begin{tabular}{|c|c|c|}
\hline Bethesda categories & Number of cases & Percentage (\%) \\
\hline 1. Unsatisfactory & 40 & 10 \\
\hline 2. Benign & [328] & [82] \\
\hline Benign follicular nodule (BFN) & 281 & 85.68 \\
\hline Hashimoto's/ Lymphocytic thyroiditis & 41 & 12.5 \\
\hline Granulomatous thyroiditis & 6 & 1.82 \\
\hline 3. AUS & 5 & 1.25 \\
\hline 4. FN/ HCN & [23] & {$[5.75]$} \\
\hline Follicular neoplasm & 15 & 65.3 \\
\hline Hürthle cell neoplasm & 8 & 34.7 \\
\hline 5. SFM & 1 & 0.25 \\
\hline 6. Malignant & [3] & {$[0.75]$} \\
\hline Papillary thyroid carcinoma [PTC] & 1 & 33.33 \\
\hline Medullary thyroid carcinoma [MTC] & 1 & 33.33 \\
\hline Undifferentiated [anaplastic] thyroid carcinoma [UTC] & 1 & 33.34 \\
\hline Total & 400 & 100 \\
\hline
\end{tabular}

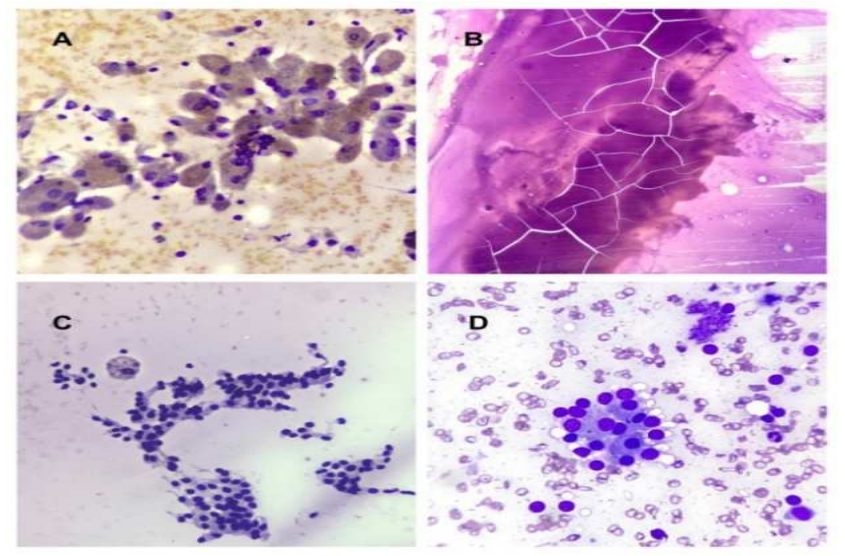

Fig 1:A: Cyst fluid only: Hemosiderin laden cyst macrophages.[PAP:40X], B: Thick colloid: Demonstrating"stained glass cracking appearance". [PAP:40X], C: BFN: Monolayer sheets of follicular cells with hemosiderin laden macrophage in the background of thin colloid. [PAP:10X], D: Graves' disease: Clustersof hyperplastic epithelial cells with 'fire flares'. [Giemsa:10X] 
Original Research Article

In the present study, out of 328 benign cases, 281 [85.68\%] cases were BFN followed by 41 [12.5\%] cases of Hashimoto's/ Lymphocytic thyroiditis and 6 [1.82\%] cases of granulomatous thyroiditis. Amongst 23 cases of FN/ HCN, there were 15 [65.3\%] cases of FN and 8 [34.7\%] cases of HCN. Only 1 [0.25\%] case was diagnosed in the SFM. 3 $[0.75 \%]$ cases in the malignant category were PTC, MTC and UTC each.

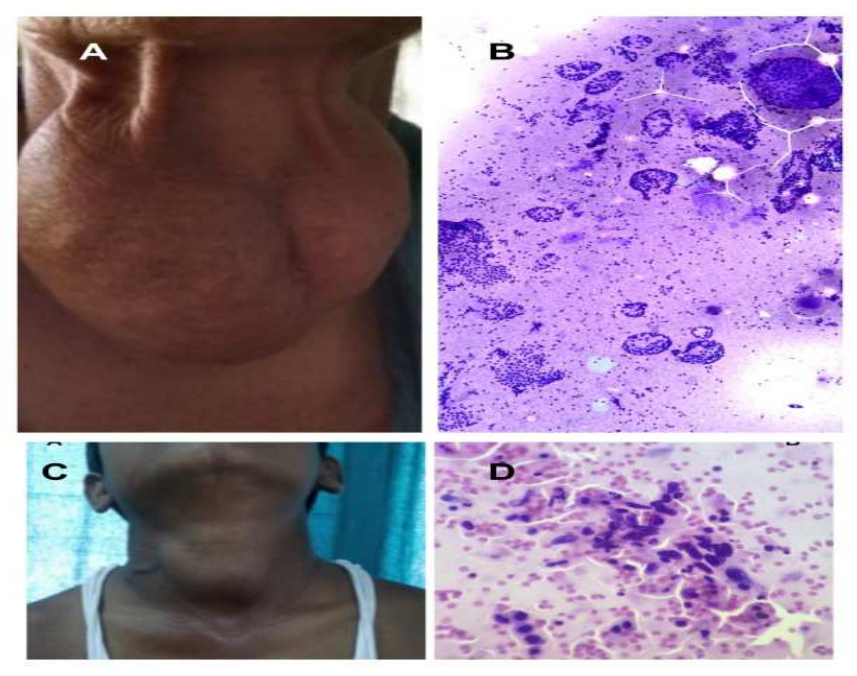

Fig. 2: A: BFN: 65 years female with nodular thyroid swelling [both lobes], B: BFN: Three dimensional variably sized balls/spheres withmonolayer sheets and macro follicular arrangement of follicular cells in the background of abundant colloid. [PAP: 4X], C: Granulomatous thyroiditis: 14 years male with diffuse thyroid swelling, D: Granulomatous thyroiditis: Mixture of epithelioid cells, histiocytes, inflammatory cells and the follicular epithelial cells [PAP:10X]
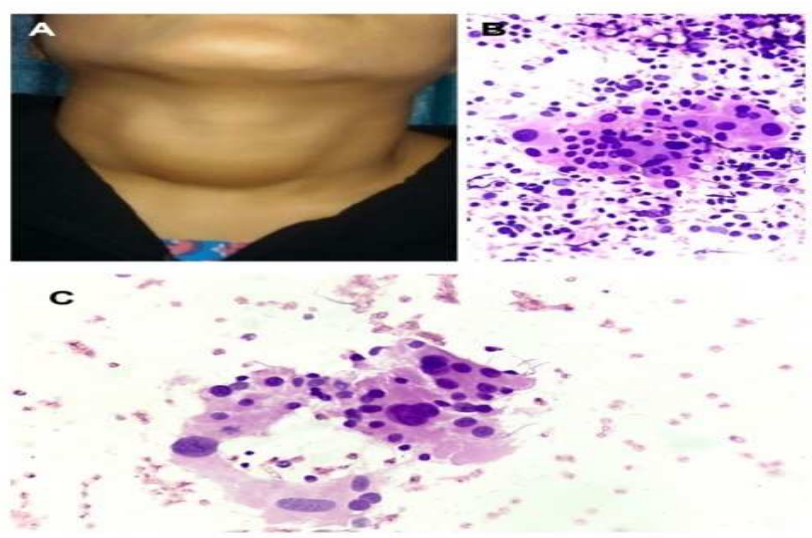

Fig-3:A: Lymphocytic/ Hashimoto thyroiditis: 28 years female with diffuse thyroid swelling, B: Lymphocytic/ Hashimoto thyroiditis:Syncytial cluster of oxyphilic cells with abundant lymphoid cells in the background[PAP:10X], C: AUS: Follicular cells admixed with atypical cells showing anisonucleosis. [PAP:10X]
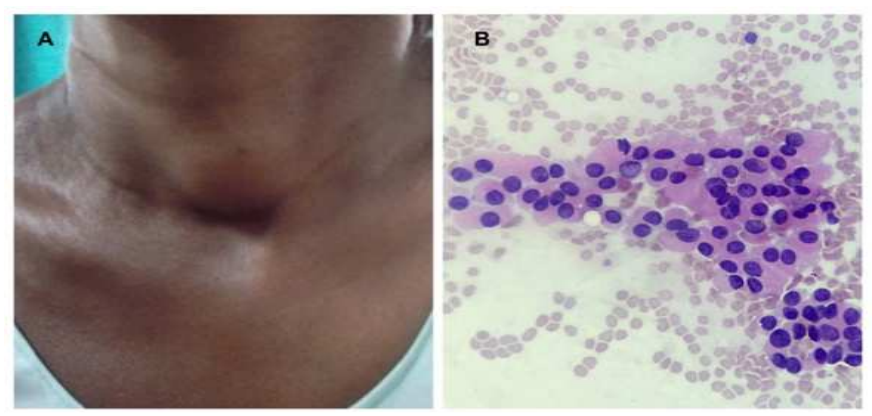

Fig-4: A: SFNHCT: 50 years old female patient with solitary thyroid swelling, B:SFNHCT: Exclusively hürthle cells with no colloid [PAP: 10X] 


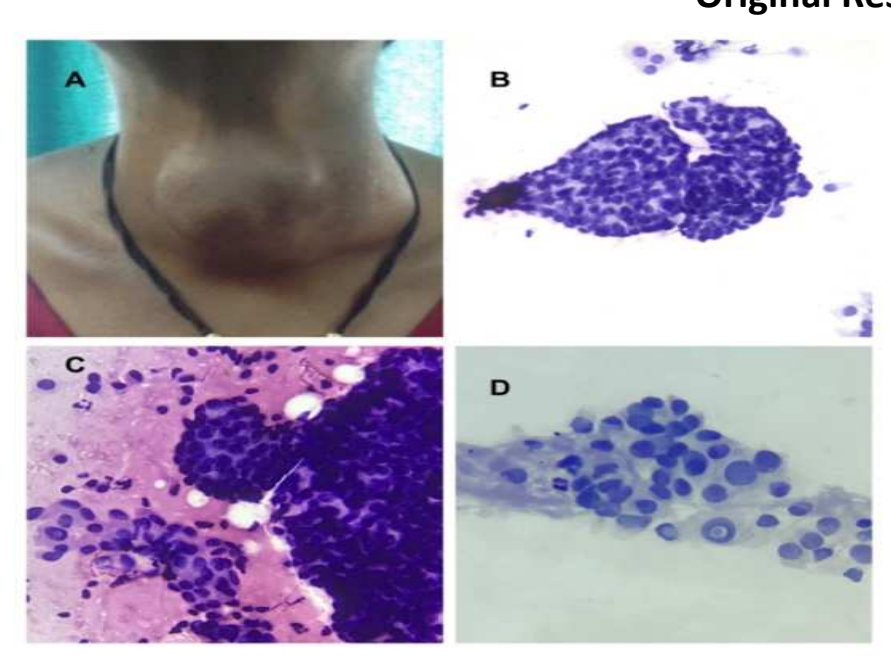

Fig-5: A: PTC: 19 years female with nodular thyroid swelling and supraclavicular lymph node enlargement. B: PTC: Syncytial sheet of cells with nuclear crowding, overlappingand distinct border forming 'finger like papilla'.[PAP:10X], C: PTC: Cell aggregates showing finger like papilla with distinct border, nuclear overlapping, crowding and intranuclear cytoplasmic inclusions.[PAP:10X], D: PTC: Cells with intranuclear cytoplasmic inclusion in a nuclei. [PAP:10X]

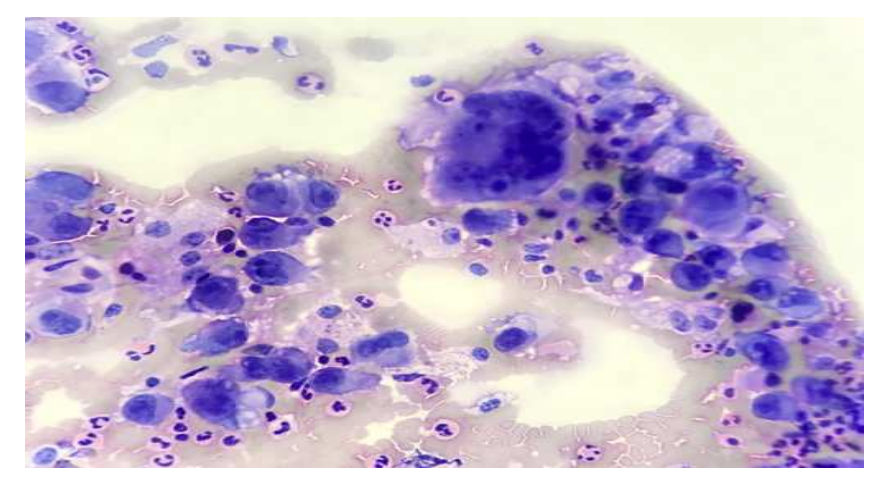

Fig-6: UTC showing highly pleomorphic cells and tumor giant cell in the background of inflammatory cells. [PAP:40X]

\section{Discussion}

The FNAC study of 400 patients with thyroid lesions was undertaken at a tertiary care hospital for a period of 3 years with the aims of studying the cytomorphological features, classifying the thyroid lesions according to the Bethesda system and to study the clinicocytopathological correlation in the patients with the thyroid lesions.

Table-5: Comparative study of FNAC diagnosis based on the Bethesda classification:

\begin{tabular}{|c|c|c|c|c|c|c|c|}
\hline \multirow{2}{*}{ Authors } & \multirow{2}{*}{ Year } & \multicolumn{6}{|c|}{ Bethesda diagnostic categories [\%] } \\
\cline { 3 - 8 } & & UNS & Benign & AUS & FN/HCN & SFM & Malignant \\
\hline Theoharis et al[5] & 2009 & 11.1 & 73.8 & 3 & 5.5 & 1.3 & 5.2 \\
\hline Jo et al [6] & 2010 & 18.6 & 59 & 3.4 & 9.7 & 2.3 & 7 \\
\hline Mufti et al [7] & 2012 & 11.6 & 77.6 & 0.8 & 4 & 2.4 & 3.6 \\
\hline Basak et al [8] & 2013 & 1.2 & 87.5 & 1.0 & 4.2 & 1.4 & 4.7 \\
\hline Bhagat et al [9] & 2014 & 5.63 & 87.5 & 0 & 3.12 & 0.63 & 3.12 \\
\hline Kantola et al [10] & 2015 & 15.8 & 69.2 & 7.4 & 2.2 & 0.7 & 4.9 \\
\hline Yasmin et al [11] & 2016 & 0.68 & 88 & 3.4 & 4.5 & 1.4 & 2.06 \\
\hline Salma et al [12] & 2016 & 6.6 & 82 & 2 & 2.5 & 1.6 & 5.1 \\
\hline Present Study & & 10 & 82 & 1.25 & 5.75 & 0.25 & 0.75 \\
\hline
\end{tabular}

In the present study, the percentage of cases in each category of TBSRTC was in accordance with Mufti et al,[7] Salma et al, [12] Theoharis et al [5] and Yasmin et al [11]. 
Original Research Article

Smears with predominantly blood or absence of colloid or an insufficient number of follicular cells or fixation artifacts were categorized as non-diagnostic [Category I]. Aspirates diagnosed as cyst fluid only [Fig.1: A] were recorded and categorized as unsatisfactory.

$40[10 \%]$ cases were unsatisfactory in our study which correlates with the findings of Theoharis et al [5] and Mufti et al[7].

Smears classified as benign [Category II] accounted for the majority i.e. 328 [82\%]. This was in agreement with the findings of all the studies mentioned in table 5 especially with the findings of Salma et al[12].

281 [85.68\%] of the 328 cases were subcategorized as BFN, while 41 cases [12.5\%] as chronic lymphocytic/ Hashimoto's thyroiditis [Fig.3: A, B] and 6 cases [1.82\%] as granulomatous thyroiditis [Fig.2: C, D]. Thus, BFN/ colloid nodule [Fig.1: B, C, D] was the commonest lesion accounting for 281 cases $(85.68 \%)$ in the benign category. This finding was in accordance with the finding of RajjaVojjala [13] who reported BFN in $82.35 \%$ of cases.

The AUS [Category III] accounted for 5 [1.25\%] cases. This finding was in accordance with Basak et al [8] Salma et al[12]. The less number of cases diagnosed as AUS in the present study could be explained by the strict adherence to diagnostic criteria mentioned in the Bethesda system.

The cases diagnosed as AUS on cytology were sparsely cellular and showed monomorphic population of small noncohesive cells resembling follicular cells with high nuclear cytoplasmic ratio having scant colloid [Fig. 3: C]. The degree of cellular or architectural atypia was not sufficient to render an interpretation of FN/ SFN/ SFM. However, because the category is heterogeneous and some what subjective, differences between observers in using this diagnosis still exist.

Because of the inability of FNAC to distinguish Follicular and Hürthle cell adenomas from their malignant counterparts, the role of thyroid FNAC shifts from being a diagnostic test to a screening test for this category of FN/ FNHCT [Category IV]. In the present study, 23 [5.75\%] cases were classified in this category which included 15 cases of FN and 8 cases of HCN. These findings were in accordance with that of Theoharis et al[5].

We categorized 15 cases as FN based on predominant arrangement of follicular cells as micro follicles or significant cell crowding having little or scant colloid in the background. The 8 cases of Hürthle cell were diagnosed as aspirate exclusively consisted of a population of loosely cohesive Hürthle cells showing marked anisonucleosis with scanty colloid in the background [Fig.4: A, B].

The SFM [Category V] was applied to the aspirates that demonstrated features of malignant neoplasm but were quantitatively or qualitatively insufficient to make a definitive diagnosis of malignancy. In our study, $1[0.25 \%]$ case had a cytological diagnosis of SFM. This finding was comparable with that of Kantola et al [10]and Bhagat et al[9].

The present case showed scanty cellularity with atypical follicular cells having hyper chromatic nuclei, binucleation and absent colloid in the background.

The malignant[Category VI] was applied to cellular aspirates with definite evidence of a malignant neoplasm. 3 [0.75\%] cases were classified as positive for malignancy. This finding was nearly similar with the finding of Yasmin et al[11] Of the 3 cases, 1 case was PTC, 1 was MTC and 1 case was UTC.

The PTC [Fig. 5: A, B, C, D] diagnosed, was characterized by the presence of follicular cells arranged in papillae and also in flat sheets. Follicular cells showed characteristics nuclear features of nuclear crowding and overlapping, irregular nuclear contours and intranuclear cytoplasmic inclusions.

The MTC demonstrated plasmacytoid cells with pleomorphic nuclei having stippled chromatin and binucleation. Intranuclear cytoplasmic d inclusions were seen in many nuclei. The UTC [Undifferentiated Thyroid Carcinoma][Fig.6] showed highly pleomorphic malignant cells with tumor giant cell formation and polymorphonuclear leukocytes in the background. 
Original Research Article

Table-6: Comparison of age distribution in various studies:

\begin{tabular}{|c|c|c|c|c|}
\hline Authors & Year & $\begin{array}{c}\text { Age range } \\
\text { (years) }\end{array}$ & $\begin{array}{c}\text { Mean age } \\
\text { (years) }\end{array}$ & $\begin{array}{c}\text { Age group [years] } \\
\text { [Maximum cases] }\end{array}$ \\
\hline Garg et al [14] & 2008 & $5-80$ & 37.69 & - \\
\hline Chandanwale et al [15] & 2012 & $18-65$ & - & $31-40$ \\
\hline Kukkar et al [16] & 2013 & $11-80$ & 41.48 & - \\
\hline Park et al [17] & 2014 & $14-86$ & 50 & $21-49$ \\
\hline Yasmin et al [11] & 2016 & $6-85$ & 40.7 & - \\
\hline Salma et al [12] & 2016 & $11-73$ & 36 & $31-40$ \\
\hline Present study & & $7-75$ & 38.53 & \\
\hline
\end{tabular}

In the present study, age range of the patients affected was from 7-75 years. This finding was in accordance with the finding of all the studies mentioned above but it was closest to Yasmin et al[11].

The mean age of the patients with the thyroid lesions in our study was 38.53 years. Our findings were comparable to Garg et al [14] and Salma et al. [12]. In the present study, maximum numbers of patients were in the age group of 31- 40 years which was similar to the finding of Chandanwale et al[15].

In the present study, thyroid lesions were more common in females with 359 [89.75\%] cases as compared to males with 41 [10.25\%] cases. Individual categories also showed a female predominance. Male: Female ratio in our study was 1:8.75 which was in accordance with the studies mentioned by Yasmin et al [11] and Kukkar et al. [16]

\section{Conclusion}

A FNAC study of 400 patients with thethyroid lesions was done in a tertiary care hospital for a period of 3 years. The cytomorphology was studied and the lesions were categorized according to The Bethesda System for Reporting Thyroid Cytopathology.

We concluded that the six-tired diagnostic approach of TBSRTC for reporting thyroid FNAC was easy to use and an excellent reporting system.

Funding: Nil, Conflict of interest: None initiated

Permission from IRB: Yes

\section{References}

1. Sclabas GM, Staerkel GA, Shapiro SE, Fornage BD, Sherman SI, Vassillopoulou-Sellin R et al. Fine needle aspiration of the thyroid and correlation with histopathology in a contemporary series of 240 patients. Am J Surg 2003; 186: 702-10.

2. Nargess G, Shahram H, Mohammad J. Fine needle aspiration cytology of thyroid nodules: correlation with surgical histopathology. Turkish J Endocrine Metabol 2008; 12: 73- 4 .

3. Ray S, Manna AK, Sen S, Pathak S, Chakraborty D, Bhattacharya P. Morphometry of thyroid lesion with cytological and histological correlation. J cytol 2006; 23: $113-8$.
4. Smadi AA, Ajarmeh K, Wreikat F. Fine needle aspiration of thyroid nodules has high sensitivity and specificity. Rawal Med J 2008; 33(2): 221- 24.

5. Theoharis CG, Schofield KM, Hammers L, Udelsman R, Chhieng DC. The Bethesda thyroid fineneedle aspiration classification system: year 1 at an academic institution. Thyroid 2009; 19:1215-23.https:// doi.org/ 10.1089/thy.2009.0155

6. Jo VY, Stelow EB, Dustin SM, Hanley KZ. Malignancy risk for fine-needle aspiration of thyroid lesions according to the Bethesda system for reporting thyroid cytopathology. Am J Clin Pathol 2010; 134: 450- 6.https://doi.org/10.1309/AJCP5N4MTHPAFXFB

7. Mufti ST, Molah R. The Bethesda system for reporting thyroid cytopathology: a five-year retrospective review of one center experience. Int $\mathrm{J}$ Health Sci 2012; 6:159- 73.

8. Basak B, Mondal S, Roy DN, Sinha S, Sinha S. The Bethesda system for reporting thyroid fine needle aspirates: A cytologic study with histologic follow-up. J Cytol 2013; 30 (2): 94-9.http://www.jcytol. org/ text. asp? 2013/30/2/94/112650

9. Bhagat VM, Tailor HJ, Kaptan KR, Baladawa V, Prasad GH, Saini PK. Diagnostic Role of the Bethesda 


\section{Original Research Article}

system for reporting thyroid lesions: effective tool for managing thyroid lesions. Global J Med Research 2014; 14:13- 18.

10. Kantola VN, Haus C, Hipp J, Zhao L, Jing X. Prospective evaluation of impact of using the Bethesda system for reporting thyroid cytopathology: an institutional experience. J Am Soc Cytopathol 2015; 4: 25-9.

11. Yasmeen K, Arsalla M, Richa DP, Erbaz M, Vinod $\mathrm{G}$, Archana $\mathrm{K}$ et.al. Classification of thyroid FNA smears into Bethesda categories and their correlation with thyroid function tests. Sch J App Med Sci 2016; 4: 916-23.

12. Salma B, Nazia B, Humaira B, Summiya F, Ruby R, Mir JN et.al. The Bethesda system for reporting thyroid cytopathology: a two-year institutional audit. Int J Cur Res Rev 2016; 8: 5- 11.

13. Vojjala R, Shankar RT. Study of cytopathological changes in thyroid by the Bethesda system. JEvidBased Med Healthc 2016; 3: 2741-44.
14. Garg S, Handa U, Mohan H, Nagarkar N. Role of fine needle aspiration cytology in diagnosis and management of thyroid lesions: A study on 434 patients. J Cytol 2008; 25: 13- 7.http://www. jcytol. org/text. asp? 2008/ 25/1/13/40652

15. Chandanwale S, Singh N, Kumar H, Pradhan P, Gore C, Rajpal M. Clinicopathological correlation of thyroid nodules. Int J Pharm Biomed Sci 2012; 3: 97- 102 .

16. Kukkar N, Malhotra V, Saluja M. Analysis of FNAC of thyroid lesions. The Internet J Pathol 2013; 15:1- 9 .

17. Park JH, Yoon SO, Son EJ, Kim HM, Nahm JH, Hong S. Incidence and malignancy rates of diagnoses in the Bethesda system for reporting thyroid aspiration cytology: an institutional experience. Korean J Pathol 2014; 48: 133- 9.https://doi.org/10.4132/KoreanJPathol. 2014.48.2.133

\section{How to cite this article?}

Dhamecha M.P, Swami S.Y, Valand A.G. FNAC study of thyroid lesions using the Bethesda system. Trop J Path Micro 2018;4(1):101-108. doi: 10.17511/jopm.2018.i1.18. 